\title{
The association of serum vitamin $D$ concentration and ventricular dysfunction among patients with acute coronary syndrome
}

This article was published in the following Dove Press journal:

Therapeutics and Clinical Risk Management

20 October 2017

Number of times this article has been viewed

\section{Kamal Khademvatani ${ }^{1}$ \\ Mirhosein Seyed \\ Mohammadzad' \\ Zahra Yekta ${ }^{2}$ \\ Omid Hadizadeh'}

'Department of Cardiology, Shohada Hospital, ${ }^{2}$ Department of Community and Preventive Medicine, Urmia University of Medical Sciences, Urmia, Iran
Correspondence: Mirhosein Seyed Mohammadzad

Department of Cardiology, Shohada Hospital, 17 Shahrivar Bolvar, Urmia 57I478334, Iran

Tel +984432375917

Email hmohammadzad@gmail.com
Objective: To determine if vitamin D deficiency was associated with higher odds of left ventricular dysfunction among patients with acute coronary syndrome (ACS) and, if so, to determine whether this association was mediated by increased inflammation as measured by C-reactive protein (CRP) and white blood cell count (WBC).

Methods: This was a cross-sectional study of 170 participants with ACS. Multiple logistic regression was used to examine the association between the outcome of ventricular performance and serum vitamin D concentrations. We also determined whether CRP and WBC meet standard criteria as the mediators between left ventricular ejection fraction and vitamin D deficiency.

Results: Participants with vitamin D deficiency were more likely to have ventricular dysfunction (OR: 2.12, 95\% CI: 1.2-5.23). WBC counts did not meet one of the criteria for mediation. However, the WBC was an effect modifier such that the association of vitamin D deficiency and ventricular dysfunction was only present among participants with WBC more than 11,000.

Conclusion: This study found that vitamin D deficiency was associated with higher odds of ventricular dysfunction. Further longitudinal and experimental studies are necessary to confirm this finding and to determine if there is a role for vitamin D supplementation therapy in preventing ventricular dysfunction in select patient populations.

Keywords: ventricular dysfunction, vitamin D deficiency, acute coronary syndrome, ejection fraction

\section{Introduction}

25 -Hydroxyvitamin $\mathrm{D}(25(\mathrm{OH}) \mathrm{D})$ deficiency is a common public health problem throughout the world. The analysis of the National Health And Nutritional Examination Survey (NHANES) estimated that the prevalence of vitamin D deficiency among adult men in the United States was 40\%. Moreover, it demonstrated an increasing trend of vitamin D deficiency among the entire population during 1990-2014. ${ }^{1}$

Acute coronary syndrome (ACS) refers to any signs or symptoms of coronary artery stenosis that includes unstable angina, non-ST segment elevation myocardial infarction (NSTEMI), and ST segment elevation myocardial infarction (STEMI). According to recent studies, there is a correlation between vitamin $\mathrm{D}$ concentrations and risk factors for coronary artery syndrome such as dyslipidemia, hypertension, obesity, diabetes mellitus, and inflammatory factors. ${ }^{2-5}$ In addition, $25(\mathrm{OH}) \mathrm{D}$ deficiency is common among patients with ACS and associated with increased risk of ACS complications. ${ }^{6}$ It has been suggested that left ventricular ejection fraction (LVEF), as a reliable indicator in ventricular 
dysfunction, has been affected more severely among patients with ACS who have low serum vitamin D concentration. ${ }^{7}$

The pathogenesis of cardiovascular disease is not fully understood, but evidence suggests that inflammation, endothelial dysfunction, and platelet aggregation may contribute to the development of ACS. ${ }^{7,8}$ The anti-inflammatory effects of $25(\mathrm{OH}) \mathrm{D}$ have been considered over several decades. Recent studies determined that vitamin D and its analogs consistently suppress proinflammatory cytokines and increase anti-inflammatory markers in the bloodstream. ${ }^{8,9}$ Akbas et al reported the inflammatory regulation role of vitamin D in their study. They presented the ratio of neutrophils-to-lymphocytes and platelets-to-lymphocytes, as an inexpensive, universally available inflammatory markers. ${ }^{10}$ The result of their study revealed an inverse association between serum vitamin $\mathrm{D}$ and novel inflammatory markers. ${ }^{10}$

Blood cytology is commonly applied to predict outcomes among patients with ACS. Anemia is associated with increased rate of hospital mortality. ${ }^{11,12}$ Leukocytosis is also linked to a significantly higher risk of heart failure, and mortality among patients with ACS. ${ }^{12}$ Thrombocytosis may cause dysregulation of coagulation, with an increased risk of severe complications. For this reason, one of the potential pharmacodynamic pathways for some medications like statin is control of the platelet aggregation response by activating vitamin D metabolites, which may lead to improvement in symptoms of ACS and could also reduce the risk of developing ventricular dysfunction. ${ }^{13}$

Given that 25(OH)D deficiency induces endothelial damage by inflammatory dysregulation and platelet aggregation and, based on the absence of studies exploring the effect of vitamin D deficiency on inflammatory markers and its prognosis among patients with ACS, we aimed to determine whether $25(\mathrm{OH}) \mathrm{D}$ deficiency is associated with ventricular dysfunction among patients with ACS. Given some published evidence that vitamin D reduces the concentration of inflammatory markers in the blood, we evaluated the role of the white blood cell (WBC) count, and C-reactive protein (CRP) as the mediators in this study.

\section{Materials and methods}

This cross-sectional study was conducted at Seyedo Shohada teaching Hospital between May 2015 and June 2016 in Urmia, Iran.

Patients with a final diagnosis of unstable angina, ST segment elevation, and non-ST segment elevation MI were considered to have ACS in this study. Myocardial infarction (MI) is defined by two of the following criteria.
1) Symptoms/signs of myocardial infarction or unstable angina which are confirmed by cardiologist. 2) Electrocardiographic findings which are compatible with the diagnosis of myocardial infarction. 3) Biochemical markers of myocardial injury to establish myocardial damage (Creatine kinase-MB [CK-MB] or Cardiac troponin).

The project was reviewed and approved by the Urmia University of Medical Sciences Institutional Board. The Social Determinant of Health Research Center of Urmia Medical Sciences University also approved the study design. The aim of this study and possible harm were explained to each participant. Patients signed the consent form to confirm their awareness of all procedures.

Blood samples were obtained within the first few hours after admission and delivered to the reference laboratory. Serum 25(OH)D (ng/mL) concentration was quantified by electrochemiluminescence (ECL) using Cobas E44 analyzer.

According to the Institute Of Medicine expert committee (IOM), we defined 25(OH)D deficiency as a serum concentration of less than $10 \mathrm{ng} / \mathrm{dL}$. Moreover, we categorized $25(\mathrm{OH}) \mathrm{D}$ concentration as a categorical variable defined as normal, insufficient, and deficient levels of vitamin D in this study. Patients with vitamin D concentrations between 10 and $20 \mathrm{ng} / \mathrm{mL}$ were defined as being of insufficient levels.

Demographic and behavioral characteristics including age, sex, settlement classification (rural/urban areas), smoking status (never, ex-smoker, and current smoker), and body mass index $\left(<25,25-30\right.$, and $\left.\geq 30 \mathrm{~kg} / \mathrm{m}^{2}\right)$ were potential confounders.

Diabetes, hypertension, ST and non-ST segment elevation MI, the season of admission, leukocytosis, anemia, thrombocytosis, and CRP were other covariates in this study. Patients who had reported taking antidiabetic/antihypertensive agents for at least 6 months were considered as diabetic/hypertensive patients in this study.

Anemia was defined as a hemoglobin level of less than $12 \mathrm{mg} / \mathrm{dL}$ in women and less than $14 \mathrm{mg} / \mathrm{dL}$ in men. Positive CRP was defined as the CRP level $\geq 10 \mathrm{mg} / \mathrm{dL}$.

The normal range of WBC was 4,500-11,000. Platelet count between 350,000 and 100,000 was considered as the normal level.

Left ventricular ejection fraction (LVEF) was the outcome variable. Echocardiography was performed for all patients by using two-dimensional echocardiography within 3-7 days of admission. Simpson, BAL estimation eye methods were used to measure LVEF. An ejection fraction of less than $45 \%$ was identified as left ventricular dysfunction. 


\section{Statistical analysis}

Descriptive statistics were reported as mean (standard deviation) or median (interquartile range, IQR) for continuous variables, and as frequency (percentage) for categorical variables. For comparisons of patients with $25(\mathrm{OH}) \mathrm{D}$ deficiency versus those with normal concentration, chi-square tests were used to compare categorical variables. Student's $t$-test and the Wilcoxon rank-sum test were used to compare continuous variables, as appropriate.

Multivariable logistic regression models were fit to explore the association between $25(\mathrm{OH}) \mathrm{D}$ concentration and ventricular dysfunction. The model was then adjusted for demographic characteristics (age, sex, and settlements classification) as potential confounder variables. Next, we adjusted for behavioral and other covariates (BMI, smoking, blood pressure, diabetes, leukocytosis, anemia, and CRP).

Furthermore, we determined whether the inflammatory markers, including CRP and WBC, met the standard criteria as mediators between 25(OH)D deficiency and patient prognosis, as measured by LVEF. Logistic regression analysis was conducted to evaluate the following hypotheses: 1) the inflammatory markers (CRP, WBC) are associated with 25(OH)D deficiency; 2) 25(OH)D is significantly associated with ventricular dysfunction; 3 ) the inflammatory markers are associated with ventricular dysfunction; and 4) the effect of 25(OH)D deficiency on the odds of developing ventricular dysfunction is attenuated when inflammatory markers are added to the model. It is necessary to reject the null of all four hypotheses to support CRP and WBC as mediator variables.

STATA version 13 was used for analysis. Statistical significance was defined using a two-sided $P$-value $<0.05$ for all analyses.

\section{Results}

\section{Characteristics of study population}

In total, 170 patients with an ACS diagnosis were included in the analysis. The mean age of the study population was $59.42 \pm 13.60$ years. Participants were mostly male (69.41\%) and from the urban areas $(65.29 \%)$. The study population was mostly admitted in the winter and fall (74.1\%). The prevalence of having non-ST segment elevation MI was $35.50 \%$. Almost half of the patients with ACS had normal blood pressure. Approximately half had no history of smoking, compared to $36.47 \%$ who were current smokers. Seventy-eight percent of participants were CRP positive. Forty-seven percent of patients had leukocytosis. The prevalence of left ventricular dysfunction was $62.9 \%$.
Comparison of participants with normal $25(\mathrm{OH}) \mathrm{D}$ concentrations and those with $25(\mathrm{OH}) \mathrm{D}$ deficiency

Eighty-four percent (142/170) of study population had low $25(\mathrm{OH}) \mathrm{D}$ concentrations. Table 1 compares the demographic characteristics between two groups. Participants with 25(OH)D deficiency were more likely to be younger ( $P=0.002)$, but were less likely to be male and smokers than those with normal 25(OH)D concentrations; however, the differences were not significant statistically. Anemia was more common among patients with 25(OH)D deficiency $(68.2 \%$ vs $31.8 \%, P=0.02)$. Patients with $25(\mathrm{OH}) \mathrm{D}$ deficiency were more likely to have leukocytosis than those with normal $25(\mathrm{OH}) \mathrm{D}$ concentration $(P=0.04)$. However, the two groups did not differ according to other demographic, clinical, and laboratory variables.

\section{Association of $25(\mathrm{OH}) \mathrm{D}$ deficiency and left ventricular dysfunction}

We examined the association of 25(OH)D deficiency and ventricular dysfunction using logistic regression analysis. As shown in Table 2, the first unadjusted model showed a higher odds of ventricular dysfunction associated with 25(OH)D deficiency (OR: 2.12, 95\% confidence interval [CI]: 1.2-5.23). A similar result was found after adjusting for demographic and behavioral variables (age, sex, settlement classification, BMI, and smoking status). Further adjustment for clinical and laboratory characteristics (hypertension, diabetes, anemia, leukocytosis, type of MI, etc.) did not meaningfully change the association (Table 2).

Subsequently, logistic regression analysis was used to determine the association between $25(\mathrm{OH}) \mathrm{D}$ concentrations as a categorical variable (normal, insufficient, or deficient) and ventricular dysfunction. Patients with 25(OH)D insufficiency were less likely to have ventricular dysfunction even after adjustment for demographic and clinical variables, compared to patients with $25(\mathrm{OH}) \mathrm{D}$ deficiency; however, the odds ratio was not significant statistically (OR: $0.72 ; 95 \% \mathrm{CI}$ : $0.33-0.92$ vs OR $2.25,95 \%$ CI: $0.84-6.04)$. Figure 1 shows the prevalence of ventricular dysfunction and vitamin $\mathrm{D}$ deficiency in the study population.

\section{Inflammatory markers (CRP and WBC) as the mediator factors}

The four criteria necessary to establish CRP and WBC as the mediators of the association between 25(OH)D deficiency and ventricular dysfunction are listed in Table 3. 
Table I Baseline characteristics by serum vitamin D level among patients with acute coronary syndrome

\begin{tabular}{|c|c|c|c|c|}
\hline $\begin{array}{l}\text { Demographic } \\
\text { and clinical } \\
\text { characteristics }\end{array}$ & $\begin{array}{l}\text { Total sample } \\
(n=\mid 70) \\
\text { Mean } \pm \text { SD }\end{array}$ & $\begin{array}{l}\text { Normal vitamin D } \\
\text { level }(\mathbf{n}=\mathbf{2 8}) \\
\text { Mean } \pm \text { SD or } \%\end{array}$ & $\begin{array}{l}\text { Deficient vitamin D } \\
(n=\mid 42) \\
\text { Mean } \pm \text { SD or } \%\end{array}$ & $\begin{array}{l}{ }^{\text {a }} \text { Test } \\
\text { statistics } \\
P \text {-value }\end{array}$ \\
\hline Age years & $59.42 \pm 13.60$ & $68.10 \pm 10.48$ & $57.7 \mid \pm 13.52$ & 0.002 \\
\hline Sex, male & 69.41 & 57.14 & 71.83 & 0.09 \\
\hline Urban settlement & 65.29 & 57.14 & 66.90 & 0.21 \\
\hline \multicolumn{5}{|l|}{ Cigarette smoking } \\
\hline Never & 51.18 & 57.14 & 50 & \\
\hline Ex-smoker & 12.35 & 0 & 14.79 & \\
\hline Current smoker & 36.47 & 42.86 & 35.21 & \\
\hline \multicolumn{4}{|l|}{ Previous MI } & 0.21 \\
\hline Yes & 11.76 & 17.86 & 10.56 & \\
\hline No & 88.24 & 82.14 & 89.44 & \\
\hline \multicolumn{4}{|l|}{ Season of MI } & 0.94 \\
\hline Fall & 30.6 & 28.57 & 30.99 & \\
\hline Winter & 43.5 & 42.86 & 43.66 & \\
\hline Spring & 14.1 & 17.86 & 11.97 & \\
\hline Summer & 11.8 & $10.7 \mid$ & 13.38 & \\
\hline \multicolumn{4}{|l|}{ Blood pressure } & 0.56 \\
\hline Normal & 50.30 & 50 & 50.35 & \\
\hline Hypertension & 49.70 & 50 & 49.65 & \\
\hline \multicolumn{4}{|l|}{ Type of MI } & 0.49 \\
\hline ST elevation & 64.50 & 66.67 & 64.08 & \\
\hline Non-ST elevation & 35.50 & 33.33 & 35.92 & \\
\hline \multicolumn{4}{|l|}{$C R P \geq 10$} & 0.88 \\
\hline Yes & 78.24 & 82.14 & 77.46 & \\
\hline No & 21.76 & 17.86 & 22.54 & \\
\hline \multicolumn{4}{|c|}{ Leukocytosis (WBC > II,000) } & $0.04 I$ \\
\hline Yes & 47.6 & 32.14 & 52.11 & \\
\hline No & 54.4 & 67.86 & 47.89 & \\
\hline \multicolumn{4}{|l|}{ Anemia } & 0.02 \\
\hline Yes & 68.2 & 78.57 & 57.75 & \\
\hline No & 31.8 & 21.42 & 42.55 & \\
\hline \multicolumn{4}{|l|}{ Thrombocytosis } & 0.25 \\
\hline Yes & 6.7 & 7.14 & 2.82 & \\
\hline No & 93.3 & 92.86 & 97.18 & \\
\hline \multicolumn{4}{|l|}{ Ejection fraction } & 0.04 \\
\hline$<45$ & 62.94 & 78.57 & 59.86 & \\
\hline$\geq 45$ & 37.06 & 21.43 & 40.14 & \\
\hline \multicolumn{4}{|l|}{ Body mass index } & 0.26 \\
\hline$<25$ & 38.2 & 739.29 & 28.17 & \\
\hline$\geq 25$ & 61.8 & 60.71 & 71.83 & \\
\hline \multicolumn{4}{|l|}{ Diabetes } & 0.42 \\
\hline Yes & 85.65 & 89.29 & 80.28 & \\
\hline No & 14.35 & $10.7 \mid$ & 19.72 & \\
\hline
\end{tabular}

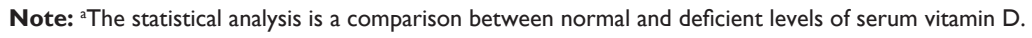

Abbreviations: MI, myocardial infarction; WBC, white blood cell.

The 25(OH)D deficiency was significantly associated with WBC. Moreover, there was a significant association between WBC and ventricular dysfunction. The odds ratio of 25(OH)D deficiency and ventricular dysfunction was attenuated after adjustment for WBC, but not to a clinically meaningful extent. Only one out of four null hypotheses was rejected for CRP as a mediator. Therefore, both WBC and CRP did not meet the criteria of being mediators in the association of $25(\mathrm{OH}) \mathrm{D}$ deficiency and ventricular dysfunction.

\section{Further analysis}

The stratified regression analysis for WBC, after adjustment for demographic, clinical, and laboratory characteristics, shows that there was a statistically significant association between $\mathrm{WBC}$ and $25(\mathrm{OH}) \mathrm{D}$ deficiency. As a result, the next analysis was stratified by WBC. There was no significant association between 25(OH)D concentrations and ejection fraction among patients with normal WBC. However, the unadjusted model for patients with $\mathrm{WBC}>11,000$ showed 
Table 2 Results of multivariable adjusted logistic regression examining the association of ventricular dysfunction with vitamin D deficiency

\begin{tabular}{|c|c|c|c|c|c|c|}
\hline & \multicolumn{2}{|l|}{ Unadjusted } & \multicolumn{2}{|c|}{ Socio-demographic adjusted } & \multicolumn{2}{|c|}{ Clinical covariates adjusted } \\
\hline & OR (Cl 95\%) & $P$-value & OR (Cl 95\%) & $P$-value & OR (Cl 95\%) & $P$-value \\
\hline \multicolumn{7}{|l|}{ Vitamin D level } \\
\hline Normal & Reference & & & & & \\
\hline Deficient & $2.45(1.25-4.32)$ & 0.03 & $2.12(1.2-5.23)$ & 0.04 & $1.99(\mathrm{I} .0 \mathrm{I}-6.2 \mathrm{I})$ & 0.05 \\
\hline Female sex & & & $1.47(1.3-4.2)$ & 0.04 & I. $10(0.44-2.72)$ & 0.81 \\
\hline Age $\geq 55$ & & & $1.19(1.21-5.20)$ & 0.03 & $1.02(0.99-1.05)$ & 0.10 \\
\hline Rural area & & & $1.2(0.88-7.1)$ & 0.21 & $1.22(0.56-2.62)$ & 0.60 \\
\hline \multicolumn{7}{|l|}{ Smoking } \\
\hline Never & & & Reference & & & \\
\hline Ex-smoker & & & $2.42(0.78-7.5)$ & 0.53 & $2.7(0.80-6.43)$ & 0.1 \\
\hline Current smoker & & & $1.57(0.99-3.39)$ & 0.05 & $2.0(0.99-4.36)$ & 0.09 \\
\hline \multicolumn{7}{|l|}{ BMI $\left(\mathrm{kg} / \mathrm{m}^{2}\right)$} \\
\hline$<25$ & & & Reference & & & \\
\hline$\geq 25-30$ & & & $\mathrm{I} .46(0.68-3.2)$ & 0.32 & $2.05(0.89-4.72)$ & 0.08 \\
\hline$>30$ & & & $0.74(0.38-1.96)$ & 0.55 & $1.15(0.39-3.98)$ & $0.7 \mathrm{I}$ \\
\hline \multicolumn{7}{|l|}{ Ml type } \\
\hline Non-ST & & & & & Reference & \\
\hline ST elevation & & & & & $2.1(1.06-4.32)$ & 0.04 \\
\hline Leukocytosis & & & & & $1.65(0.84-3.12)$ & 0.22 \\
\hline Diabetes & & & & & I.64 (0.75-3.44) & 0.24 \\
\hline Blood pressure & & & & & $1.23(0.89-5.65)$ & 0.12 \\
\hline Anemia & & & & & $2.1(0.98-4.78)$ & 0.18 \\
\hline
\end{tabular}

Abbreviations: BMI, body mass index; MI, myocardial infarction.

the association between $25(\mathrm{OH}) \mathrm{D}$ deficiency and ventricular dysfunction; even after adjusting the model for demographic variables, the OR was more than one, which demonstrated that patients with $25(\mathrm{OH}) \mathrm{D}$ deficiency were more likely to develop ventricular dysfunction among those with leukocytosis (OR: 2.11, 95\% CI: 1.41-6.37). The result remained identical after adding clinical characteristics to the model.

\section{Discussion}

Worldwide, ACS is one of the important causes of heart failure. Although the pathophysiology of ACS is not fully understood, evidence suggests that inflammation and endothelial dysfunction are part of the biological pathway to develop ACS.

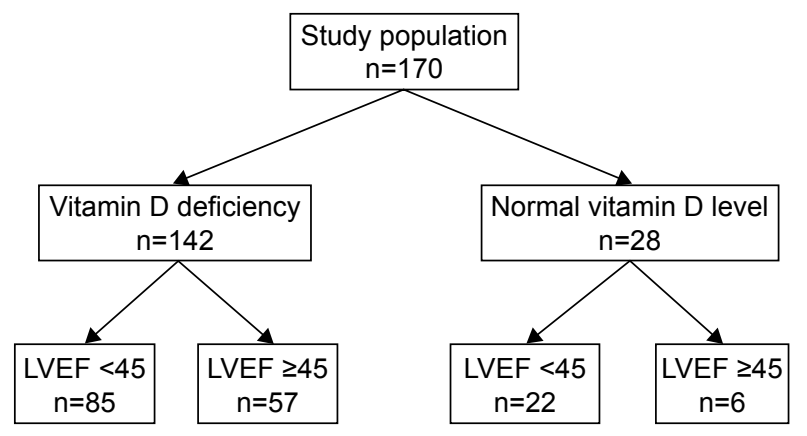

Figure I Left ventricular dysfunction (LVEF $<45$ ) among patients with vitamin D deficiency and those with normal serum vitamin $D$ concentration.
Studies of the general population have concluded that vitamin D deficiency is associated with diabetes, cardiovascular disease, and poor physical function. Previous reports have suggested that $25(\mathrm{OH}) \mathrm{D}$ is a precursor of several hormones which may contribute to cardioprotective function, inflammatory response, and the thrombotic process in the pathogenesis of atherosclerosis. ${ }^{6,13}$ There is now mounting evidence that explains the role of vitamin $\mathrm{D}$ in the functioning of immune regulatory pathways. It has been suggested that there is an association between inflammatory markers such as CRP and/or WBC and 25(OH)D concentrations. In fact, the vitamin $\mathrm{D}$ receptor has been identified on inflammatory cells, where the active metabolites of vitamin D inhibit leukocyte proliferation, cytokine release, and the platelet aggregation process. ${ }^{13-16}$ Our study represents the first attempt to define the impact of serum vitamin D concentration and ventricular dysfunction in consideration of inflammatory marker activity.

Our study found a significant association between 25(OH)D deficiency and increased prevalence of ventricular dysfunction among patients. CRP and WBC did not meet the criteria as the mediators. WBC was an effect modifier: only patients with leukocytosis were found to have a significant association with increased odds of developing ventricular dysfunction. These results suggest that vitamin D concentration could be an important tool in the prediction of ACS 
Table 3 Criteria to establish CRP and WBC as mediators in the association between serum vitamin $D$ and ventricular dysfunction

\begin{tabular}{|c|c|c|}
\hline Criteria results & OR & Cl $95 \%$ \\
\hline \multicolumn{3}{|l|}{ WBC } \\
\hline $\begin{array}{l}\text { Vitamin D deficiency is } \\
\text { significantly associated with } \\
\text { WBC }\end{array}$ & 2.1 & $(1.22-4.38)^{*}$ \\
\hline $\begin{array}{l}\text { WBC is significantly } \\
\text { associated with ventricular } \\
\text { Ejection fraction }\end{array}$ & 1.7 & $(1.42-5.21)^{*}$ \\
\hline $\begin{array}{l}\text { Vitamin D deficiency is } \\
\text { significantly associated with } \\
\text { Ventricular ejection fraction }\end{array}$ & 2.45 & $(1.25-4.32)^{*}$ \\
\hline \multicolumn{3}{|l|}{ on the odds of developing } \\
\hline \multicolumn{3}{|l|}{$\begin{array}{l}\text { Ventricular dysfunction is } \\
\text { attenuated when }\end{array}$} \\
\hline \multicolumn{3}{|l|}{ WBC is added to the model } \\
\hline \multicolumn{3}{|l|}{ CRP } \\
\hline $\begin{array}{l}\text { Vitamin D deficiency is } \\
\text { significantly associated with } \\
\text { CRP }\end{array}$ & 1.36 & $(0.96-5.34)$ \\
\hline $\begin{array}{l}\text { CRP is significantly associated } \\
\text { with ventricular } \\
\text { Ejection fraction }\end{array}$ & 2.65 & $(0.77-7.54)$ \\
\hline $\begin{array}{l}\text { Vitamin D deficiency is } \\
\text { significantly associated with } \\
\text { Ventricular ejection fraction }\end{array}$ & 2.45 & $(1.25-4.32)^{*}$ \\
\hline $\begin{array}{l}\text { The effect of serum vitamin } D \\
\text { on the odds of developing }\end{array}$ & 1.2 & $(0.55-5.99)$ \\
\hline $\begin{array}{l}\text { Ventricular dysfunction is } \\
\text { attenuated when }\end{array}$ & & \\
\hline CRP is added to the model & & \\
\hline
\end{tabular}

Note: $* p<0.05$.

Abbreviations: CRP, C-reactive protein; WBC, white blood cell.

outcomes, although additional prospective studies are needed to confirm these results.

In our study, WBC did not meet one of the conventional criteria as a mediator. On examining CRP as a mediator, it could not meet the criteria as well. One potential explanation is CRP and WBC were the only systemic inflammatory markers measured in this study, but other biomarkers of inflammation may act as the mediators in the relationship of vitamin D and inflammation. Another reason is the fact that our sample size may have been too small to explore the role of WBC and CRP as the mediators.

Although in vitro studies have suggested that vitamin D and its active metabolites play a proinflammatory suppressive role with increasing anti-inflammatory cytokines, ${ }^{7,17}$ the results of clinical trial studies to prove the anti-inflammatory effect of vitamin D have been inconsistent. ${ }^{17-19}$ A clinical trial conducted by Schleithoff et al indicated that 9 months of vitamin D supplementation therapy in patients with heart failure reduced the inflammatory biomarkers, as measured by the serum interleukin and tumor necrosis factor (TNF-a). ${ }^{17}$ In contrast, another study showed that vitamin D administration among patients with diabetes did not significantly alter serum biomarkers of inflammation and oxidative stress. ${ }^{19}$ Moreover, there is contradictory evidence with regard to the association of CRP and cardiovascular outcomes. ${ }^{20}$

Our study revealed that $25(\mathrm{OH}) \mathrm{D}$ deficiency had a significant effect on increasing the odds of left ventricular dysfunction. Correia et al demonstrated the potential association between $25(\mathrm{OH}) \mathrm{D}$ and hospital mortality among patients with ACS. ${ }^{21}$ Similarly, another cross-sectional study presented a significant association between serum vitamin D concentrations and ventricular ejection fraction. ${ }^{22}$ A link between vitamin $\mathrm{D}$ deficiency and the severe outcomes of ACS among patients with diabetes has been suggested by Gondim et al. ${ }^{23}$ Verdoia et al indicated that low vitamin D concentration is highly associated with adverse outcomes in women suffering from cardiovascular diseases. ${ }^{24}$ Survival analysis for 7-year total mortality rate among patients with ACS showed a correlation between vitamin D deficiency and increased rate of mortality. ${ }^{5}$ A prospective study proposed a possible association between vitamin D deficiency, elevated cholesterol levels, and inflammatory markers. ${ }^{25}$

We found that the prevalence of left ventricular dysfunction was higher among patients with leukocytosis and $25(\mathrm{OH}) \mathrm{D}$ deficiency, but not among those with normal $\mathrm{WBC}$ and low serum vitamin D. It is possible that the systemic effect of increasing WBC may alter the association of vitamin D concentration and ventricular dysfunction through inflammatory pathways. ${ }^{13,16}$

Limitations of this study need to be acknowledged. The cross-sectional design prevents any inferences of causality. In our study, serum vitamin D concentration and ventricular ejection fraction were evaluated at a single time point. However, a cross-sectional design is appropriate for hypothesis generation. Unmeasured confounders are another challenging issue. Information about patient health behavior, lifestyle, and medication history which may influence the ACS prognosis were not measured in our study. Our study included no variables of socioeconomic factors which may be linked to vitamin D status. ${ }^{26}$ Short-term follow-up is also another limitation in this study. Moreover, this study ignored the severity of ventricular dysfunction by categorizing ejection fraction as a binary variable because of small sample size; future larger studies may benefit from examining ventricular dysfunction as a non-dichotomized outcome.

\section{Disclosure}

The authors report no conflicts of interest in this work. 


\section{References}

1. Kim DH, Sabour S, Sagar UN, Adams S, Whellan DJ. Prevalence of hypovitaminosis D in cardiovascular diseases (from the National Health and Nutrition Examination Survey 2001 to 2004). Am J Cardiol. 2008;102(11):1540-1544.

2. Lavie CJ, Lee JH, Milani RV. Vitamin D and cardiovascular disease will it live up to its hype? J Am Coll Cardiol. 2011;58(15):1547-1556.

3. Makariou S, Liberopoulos E, Florentin M, et al. The relationship of vitamin $\mathrm{D}$ with non-traditional risk factors for cardiovascular disease in subjects with metabolic syndrome. Arch Med Sci. 2012;8(3):437-443.

4. Giovannucci E, Liu Y, Hollis BW, Rimm EB. 25-hydroxyvitamin D and risk of myocardial infarction in men: a prospective study. Arch Intern Med. 2008;168(11):1174-1180.

5. Naesgaard PA, Pönitz V, Aarsetoey H, et al. Prognostic utility of vitamin D in acute coronary syndrome patients in coastal Norway. Dis Markers. 2015;2015:283178.

6. Kunadian V, Ford GA, Bawamia B, Qiu W, Manson JE. Vitamin D deficiency and coronary artery disease: a review of the evidence. Am Heart J. 2014;167(3):283-291.

7. Carvalho LS, Sposito AC. Vitamin D for the prevention of cardiovascular disease: are we ready for that? Atherosclerosis. 2015;241(2): $729-740$

8. Kudo K, Hasegawa S, Suzuki Y, et al. 1 $\alpha, 25$-Dihydroxyvitamin $\mathrm{D}(3)$ inhibits vascular cellular adhesion molecule-1 expression and interleukin-8 production in human coronary arterial endothelial cells. J Steroid Biochem Mol Biol. 2012;132(3-5):290-294.

9. Sokol SI, Srinivas V, Crandall JP, et al. The effects of vitamin D repletion on endothelial function and inflammation in patients with coronary artery disease. Vasc Med. 2012;17(6):394-404.

10. Akbas EM, Gungor A, Ozcicek A, Akbas N, Askin S, Polat M. Vitamin D and inflammation: evaluation with neutrophil-to-lymphocyte ratio and platelet-to-lymphocyte ratio. Arch Med Sci. 2016;12(4):721-727.

11. Kalra PR, Greenlaw N, Ferrari R, et al; ProspeCtive observational LongitudinAl RegIstry oF patients with stable coronary arterY disease (CLARIFY) Investigators. Hemoglobin and change in hemoglobin status predict mortality, cardiovascular events, and bleeding in stable coronary artery disease. Am J Med. 2017;130(6):720-730.

12. Tomaszuk-Kazberuk A, Bolińska S, Młodawska E, Łopatowska P, Sobkowicz B, Musiał W. Does admission anaemia still predict mortality six years after myocardial infarction? Kardiol Pol. 2014;72(6): 488-493.

13. Verdoia M, Pergolini P, Rolla R, et al; Novara Atherosclerosis Study Group (NAS). Impact of high-dose statins on vitamin D levels and platelet function in patients with coronary artery disease. Thromb Res. 2017;150:90-95.
14. Verdoia M, Schaffer A, Sartori C, et al. Vitamin D deficiency is independently associated with the extent of coronary artery disease. Eur J Clin Invest. 2014;44(7):634-642.

15. van Etten E, Mathieu C. Immunoregulation by 1,25-dihydroxyvitamin D3: basic concepts. J Steroid Biochem Mol Biol. 2005;97(1-2): 93-101.

16. Silvagno F, De Vivo E, Attanasio A, Gallo V, Mazzucco G, Pescarmona G. Mitochondrial localization of vitamin D receptor in human platelets and differentiated megakaryocytes. PLoS One. 2010;5(1):e8670.

17. Schleithoff SS, Zittermann A, Tenderich G, Berthold HK, Stehle P, Koerfer R. Vitamin D supplementation improves cytokine profiles in patients with congestive heart failure: a double-blind, randomized, placebo-controlled trial. Am J Clin Nutr. 2006;83(4):754-759.

18. Das M, Tomar N, Sreenivas V, Gupta N, Goswami R. Effect of vitamin D supplementation on cathelicidin, IFN- $\gamma$, IL-4 and Th1/Th2 transcription factors in young healthy females. Eur J Clin Nutr. 2014; 68(3):338-343.

19. Yiu YF, Yiu KH, Siu CW, et al. Randomized controlled trial of vitamin D supplement on endothelial function in patients with type 2 diabetes. Atherosclerosis. 2013;227(1):140-146.

20. Milazzo V, De Metrio M, Cosentino N, Marenzi G, Tremoli E. Vitamin D and acute myocardial infarction. World J Cardiol. 2017;9(1):14-20.

21. Correia LC, Sodré F, Garcia G, et al. Relation of severe deficiency of vitamin $\mathrm{D}$ to cardiovascular mortality during acute coronary syndromes. Am J Cardiol. 2013;111(3):324-327.

22. Pilz S, März W, Wellnitz B, et al. Association of vitamin D deficiency with heart failure and sudden cardiac death in a large cross-sectional study of patients referred for coronary angiography. J Clin Endocrinol Metab. 2008;93(10):3927-3935.

23. Gondim F, Caribé A, Vasconcelos KF, Segundo AD, Bandeira F. Vitamin D deficiency is associated with severity of acute coronary syndrome in patients with type 2 diabetes and high rates of sun exposure. Clin Med Insights Endocrinol Diabetes. 2016;9:37-41.

24. Verdoia M, Schaffer A, Barbieri L, et al; Novara Atherosclerosis Study Group (NAS). Impact of gender difference on vitamin D status and its relationship with the extent of coronary artery disease. Nutr Metab Cardiovasc Dis. 2015;25(5):464-470.

25. De Metrio M, Milazzo V, Rubino M, et al. Vitamin D plasma levels and in-hospital and 1-year outcomes in acute coronary syndromes: a prospective study. Medicine (Baltimore). 2015;94(19):e857.

26. León de la Fuente RA, Naesgaard PA, Nilsen ST, et al. Socioeconomic assessment and impact of social security on outcome in patients admitted with suspected coronary chest pain in the city of salta, Argentina. Cardiol Res Pract. 2013;2013:807249.
Therapeutics and Clinical Risk Management

\section{Publish your work in this journal}

Therapeutics and Clinical Risk Management is an international, peerreviewed journal of clinical therapeutics and risk management, focusing on concise rapid reporting of clinical studies in all therapeutic areas outcomes, safety, and programs for the effective, safe, and sustained use of medicines. This journal is indexed on PubMed Central, CAS,

\section{Dovepress}

EMBase, Scopus and the Elsevier Bibliographic databases. The manuscript management system is completely online and includes a very quick and fair peer-review system, which is all easy to use. Visit http://www.dovepress.com/testimonials.php to read real quotes from published authors. 